
Kidney
Blood Pressure
Research

\title{
The Association Between Peritoneal Charge Barrier Dysfunction and Protein Lost During Continuous Ambulatory Peritoneal Dialysis
}

\author{
Guo-Qing Yu Jian Chen Jun-Xia Li \\ Department of Nephrology, Dong Fang Hospital, Fuzhou City, Fujian Province, China
}

\section{Key Words}

Amylase - Charge barrier - Continuous ambulatory peritoneal dialysis • Hypoalbuminemia • Protein Malnutrition

\begin{abstract}
Background/Aims: The main purpose of the present study was to determine the effect of peritoneal charge barrier dysfunction on hypoalbuminemia during CAPD. Methods: We measured the association of dialysis dose, peritoneal equilibration test (PET) results (ratio of dialysate and plasma creatinine), and peritoneal charge barrier index (ratio of pancreatic and salivary $\alpha$-amylase clearance) on protein loss in 33 patients on maintenance CAPD. All patients were from a single institution and were diagnosed with chronic nephritis $(n=18$ cases), diabetic nephropathy $(n=8)$, hypertension $(n=5)$, and hepatitis B virus-associated glomerulonephritis $(n=2)$. Results: The mean $( \pm S D)$ dialysate protein loss was $4.04 \mathrm{~g}( \pm 1.97)$ per day. Protein loss was positively correlated with dialysis dose $(r=0.438, p=0.01)$ but was not significantly correlated with PET results. The mean $( \pm$ SD) peritoneal charge barrier index was $6.12( \pm 21.20)$ and was inversely correlated with protein loss into the peritoneal dialysate $(r=-0.532, p<0.01)$. Conclusions: Taken together, our study of CAPD patients indicates that protein loss into the peritoneal dialysate increases with peritoneal dialysis dose and with disruption of the peritoneal charge barrier.
\end{abstract}

Copyright $@ 2013$ S. Karger AG, Basel

\section{Introduction}

Hypoalbuminemia is a major complication in patients with peritoneal dialysis and is significantly associated with increased incidence of cardiovascular events and mortality in these patients [1-3]. Hypoalbuminemia is an important consideration for improving 


\section{Kidney \\ Blood Pressure Research}

Kidney Blood Press Res 2013;37:252-258

DOI: 10.1159/000350150

Published onlıne: July 15,2013

(C) 2013 S. Karger AG, Basel

www.karger.com/kbr

Yu/Chen/Li: Factors Affecting Protein Loss During CAPD

technique survival of patients being treated with hemodialysis (HD) and peritoneal dialysis (PD) [4]. PD patients may experience hypoalbuminemia due to inflammation, inadequate dialysis, impaired appetite, or protein loss during PD $[5,6]$. The daily dialysate protein loss in PD patients can be up to $10.5 \mathrm{~g}$, most of which is albumin [7]. Thus, protein loss during CAPD can ultimately lead to hypoalbuminemia and generalized edema due to osmotic effects. It is clearly important to understand the mechanism of protein loss during CAPD in order to develop protocols that can prevent and treat this problem. Many studies have reported that patients with high peritoneal transport have poor prognosis $[8,9]$.

The peritoneum functions as a molecular and charge barrier, similar to the glomerular basement membrane [10]. Thus, it is generally believed that disruption of the peritoneal barrier will cause negatively charged molecules (such as albumin) to pass through more readily, leading to significant protein loss [11], although there is some question about the relative importance of the peritoneum as a molecular barrier vs. a charge barrier [12]. However, the effect of disruption of the peritoneal charge barrier on protein loss in PD patients has not yet been established.

The methods currently used to assess charge barrier disruption include traditional histological staining, immunohistochemical staining, biochemical assays, isotopic methods, and measurement of peritoneal clearance. These methods can be complicated, are generally not applicable in clinical practice, and are unable to accurately quantify in vivo changes of the peritoneal charge barrier [13]. Endogenous proteins have been used to measure the glomerular charge barrier [14] and may also be useful for measurement of the peritoneal charge barrier. For example, pancreatic $\alpha$-amylase (PAM) and salivary $\alpha$-amylase (SAM) have the same molecular weight $(56 \mathrm{kDa})$ and diameter $(2.9 \mathrm{~nm})$, but PAM has a neutral isoelectric point ( $\mathrm{pI}=7.0$ ) whereas SAM has an acidic isoelectric point ( $\mathrm{pI}=5.9 \sim 6.4)$ [13]. Thus, the more negatively charged form (SAM) will have a lower clearance rate than the neutral form (PAM) due to the presence of the peritoneal charge barrier, and the ratio of the clearance rates of these two $\alpha$-amylases will change upon disruption of the peritoneal charge barrier $[15,16]$.

The main purpose of the present study was to determine the effect of peritoneal charge barrier dysfunction on protein loss during CAPD.

\section{Materials and Methods}

\section{Subjects and CAPD protocol}

This study was conducted from August 2005 to August 2009 and was approved by the Institutional Review Board of Fuzhou General Hospital (Fuzhou City, China). All patients provided informed consent. The inclusion criteria were patients with primary diseases including chronic nephritis ( $\mathrm{n}=18$ cases), diabetic nephropathy $(n=8)$, hypertension $(n=5)$, and hepatitis B virus-associated glomerulonephritis $(n=2)$. The exclusion criteria were patients with peritonitis, heart or liver dysfunction, infection, inflammation, or tumors. All patients underwent CAPD 3 or 4 times per day (dwell time of $4 \mathrm{~h}$ per session) using a $1.5 \%$ glucose sodium lactate peritoneal dialysis solution, Dianeal (Baxter, Guangzhou, China), although the time was shortened for high transporters based on PET results (see below). All patients were enrolled after they were on CAPD for two months, and all measurements were performed immediately after sample collection.

\section{Biochemical measurements}

Fasting serum albumin, urea, creatinine, total cholesterol (TC), and triglycerides (TG) were measured in the morning using an automatic biochemical analyzer (AU2700, Olympus, Japan). Peritoneal urea, Kt/V, and creatinine clearance $(\mathrm{CCr})$ were then calculated. A dialysate sample $(10 \mathrm{~mL})$ was used for measurement of protein concentration and calculation of total protein loss. Peritoneal dialysate was collected at $24 \mathrm{~h}$ intervals for measurement of volume (PV) and protein (PP). Daily PV is the total amount of abdominal drainage $(\mathrm{mL})$ in $24 \mathrm{~h}$. PP was simply calculated as the product of the concentration of dialysate protein and the PV. Pancreatic $\alpha$-amylase (PAM) and total $\alpha$-amylase (TAM) were measured with kits from Randox Laboratories (Antrim, UK). 


\section{Kidney Blood Pressure Research}

Yu/Chen/Li: Factors Affecting Protein Loss During CAPD

\section{Charge barrier calculation}

Salivary $\alpha$-amylase (SAM) was calculated as the difference of PAM and TAM. The following variables were then calculated: peritoneal dialysate salivary $\alpha$-amylase (PSAM); peritoneal dialysate pancreatic $\alpha$-amylase (PPAM); serum salivary $\alpha$-amylase (SSAM); and serum pancreatic $\alpha$-amylase (SPAM). Finally, the charge barrier index was calculated as the ratio of the clearance of PAM and SAM (CPAM/CSAM), where $\mathrm{CPAM}=\mathrm{PPAM} \times$ peritoneal dialysate volume $/ \mathrm{SPAM}$ and CSAM $=\mathrm{PSAM} \times$ peritoneal dialysate volume $/$ SSAM.

\section{Peritoneal equilibration test}

Patients were divided into two groups based on peritoneal equilibration test (PET) results [17], which measured the dialysate/plasma ratio (D/P) of Cr. Dialysate samples for this test were collected after $4 \mathrm{~h}$ of dialysis. The high transport group $(n=16)$ consisted of patients who had high or high-average transport (range: 0.65-1.04), and the low transport group $(n=17)$ consisted of patients with low or low-average transport (range: 0.34-0.65).

\section{Statistical analysis}

Data are summarized as means \pm standard deviations (SDs) and median with ranges (min to max), except that sex was expressed as $\mathrm{n}(\%)$ of males. Protein measurements are summarized as means \pm SDs before and after PD and compared with a paired $t$-test. Spearman correlation analysis was performed to assess the relationship of peritoneal dialysate protein loss with peritoneal dialysate time, peritoneal dialysate dosage, $\mathrm{D} / \mathrm{P}$ of $\mathrm{Cr}$, peritoneal dialysate, and serum amylase because of non-normal distribution. The relationship of charge barrier and peritoneal dialysate protein loss was analyzed by Pearson correlation analysis. All statistical assessments were two-tailed and a $p$-value less than 0.05 was considered significant. Statistical analyses were performed using PASW 18.0 statistics software (SPSS Inc, Chicago, IL, USA).

\section{Results}

A total of 33 consecutive CAPD patients were enrolled (Table 1). There were 28 males and 5 females, the average ( \pm SD) age was 50.85 ( \pm 15.17 ) years, the average duration of dialysis was 238.03 ( \pm 220.12 days) and the average dialysis dosage was $5.82 \pm 1.16 \mathrm{~L}$ per day. Table 1 also summarizes the baseline demographic and clinical characteristics, urine analysis results, peritoneal dialysis variables, peritoneal dialysate and serum amylase activities, and charge barrier index values of all enrolled patients.

In this study, we used the equilibration between dialysate and plasma creatinine after $4 \mathrm{~h}(\mathrm{D} / \mathrm{P}$ of $\mathrm{Cr})$ to characterize transport status. Thus, we classified patients as having low transport $(\mathrm{n}=17$, range: $0.34-0.65$, mean \pm SD: $0.61 \pm 0.11)$ or high transport $(\mathrm{n}=$ 16 , range: $0.65-1.04$, mean \pm SD: $0.80 \pm 0.18$ ). The mean protein loss was not significantly different in these two groups (low transport: $3.72 \pm 2.03$, high transport: $4.36 \pm 1.91 ; p=$ $0.367)$. Correlation analysis of protein loss and peritoneal dialysis variables indicated that protein loss was positively and significantly correlated with peritoneal dialysate dosage $(\mathrm{r}=$ $0.438, p=0.011$, Figure 1). However, there was no correlation of peritoneal protein loss with albumin $(r=-0.134, p=0.457)$.

Table 2 shows the results of correlation analysis of peritoneal dialysate protein loss with peritoneal and serum dialysate $\alpha$-amylases. The results indicate that protein loss was positively correlated with peritoneal dialysate salivary $\alpha$-amylase (PSAM, $\mathrm{r}=0.426, p=$ 0.013 ), but negatively correlated with peritoneal dialysate pancreatic $\alpha$-amylase (PPAM, $\mathrm{r}=$ $-0.384, p=0.027$ ) and serum salivary $\alpha$-amylase (SSAM, $\mathrm{r}=-0.613, p<0.001$ ). There was no significant relationship of peritoneal dialysate protein loss with serum pancreatic $\alpha$-amylase (SPAM, $\mathrm{r}=-0.183, p=0.308$ ). There was a negative correlation of peritoneal electric charge and protein loss in all 33 patients $(\mathrm{r}=-0.584, p<0.01)$, but no significant difference of high transporters and low transporters.

We calculated the charge barrier index as the ratio of the clearance of PAM and SAM (CPAM/CSAM). Among all 33 patients, the mean charge ratio $( \pm$ SD) was $6.12( \pm 21.20)$ 


\section{Kidney \\ Blood Pressure Research}

Table 1. Demographic and clinical characteristics, peritoneal dialysis variables, and peritoneal dialysate and serum $\alpha$-amylase activities of enrolled patients $(n=33)$

\begin{tabular}{|c|c|c|}
\hline & Mean \pm SD & Median (Range) \\
\hline \multicolumn{3}{|l|}{ Demographic/clinical variable } \\
\hline Age, yrs & $50.85 \pm 15.17$ & $49(20$ to 80$)$ \\
\hline Sex, males $(\%)$ & $28(84.8)$ & \\
\hline Weight, kg & $61.70 \pm 8.49$ & 63 (45 to 78$)$ \\
\hline $\mathrm{SBP}, \mathrm{mmHg}$ & $142.18 \pm 14.58$ & $140(120$ to 186$)$ \\
\hline DBP, mmHg & $84.06 \pm 10.81$ & $85(51$ to 102$)$ \\
\hline Urine volume, $\mathrm{mL}$ & $1281.82 \pm 680.63$ & 1450 (50 to 3100$)$ \\
\hline $\mathrm{CCr}, \mathrm{mL} / \mathrm{min}$ & $7.95 \pm 2.54$ & $7.96(4.89$ to 16.21$)$ \\
\hline \multicolumn{3}{|l|}{ Peritoneal dialysis variable } \\
\hline Peritoneal dialysate time, days & $238.03 \pm 220.115$ & $150(60$ to 1215$)$ \\
\hline Peritoneal dialysate dosage, $\mathrm{L}$ & $5.82 \pm 1.16$ & $6(4$ to 8$)$ \\
\hline $\mathrm{D} / \mathrm{P}$ of $\mathrm{Cr}$ & $0.70 \pm 0.17$ & $0.68(0.46$ to 1.36$)$ \\
\hline Peritoneal dialysate protein loss, $\mathrm{g} / 24 \mathrm{~h}$ & $4.04 \pm 1.97$ & $4.23(0.70$ to 7.93$)$ \\
\hline \multicolumn{3}{|c|}{ Peritoneal dialysate and serum $\alpha$-amylase activity* } \\
\hline PSAM, U/L & $7.2 \pm 10.15$ & $5(1.8$ to 60.8$)$ \\
\hline PPAM, U/L & $5.14 \pm 6.4$ & $2.6(0.2$ to 30.2$)$ \\
\hline SSAM, U/L & $57.2 \pm 31.83$ & $50.2(2.4$ to 140$)$ \\
\hline SPAM, U/L & $29.95 \pm 22.65$ & $24.6(3.69$ to 91.3$)$ \\
\hline Charge barrier index ${ }^{* *}, \mathrm{CPAM} / \mathrm{CSAM}$ & $6.12 \pm 21.20$ & $0.82(0.1$ to 122.5$)$ \\
\hline \multicolumn{3}{|c|}{$\begin{array}{l}\text { Data are expressed as means } \pm \text { SDs and median with range (min to max) except for sex, which is given as n (\%) } \\
\text { males. Abbreviations: yrs, years old; SBP, systolic blood pressure; DBP, diastolic blood pressure; CCr, clearance } \\
\text { creatinine; D/P of Cr, dialysate/plasma ratio of creatinine, PSAM, peritoneal dialysate saliva } \alpha \text {-amylase; PPAM, } \\
\text { peritoneal dialysate pancreatic } \alpha \text {-amylase; SSAM, serum saliva } \alpha \text {-amylase; SPAM, serum dialysate pancreatic } \\
\alpha \text {-amylase. }{ }^{*} \text { Transperitoneal transport of amylases was measured three times and averaged for each patient. } \\
{ }^{* *} \text { Charge barrier index was calculated as the ratio of clearance of PAM and SAM (CPAM/CSAM), where CPAM = } \\
\text { PPAM } \times \text { peritoneal dialysate volume/SPAM and CSAM = PSAM } \times \text { peritoneal dialysate volume/SSAM. }\end{array}$} \\
\hline
\end{tabular}

Fig. 1. Scatter plot of peritoneal dialysate protein loss with peritoneal dialysate dosage. The coefficient of Spearman correlation analysis was observed as $0.438(\mathrm{P}=0.011)$.

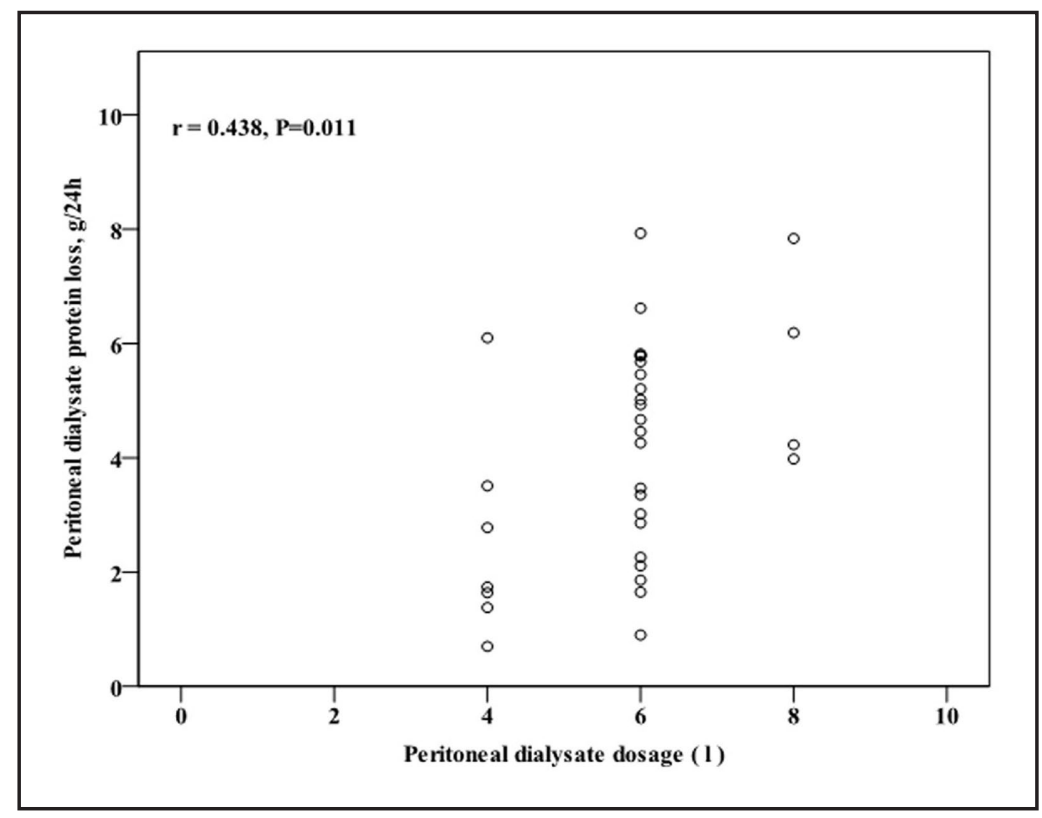

and the range was 0.1 to 122.5 (Table 1). Finally, we analyzed the correlation of peritoneal dialysate protein loss with Ln(CPAM/CSAM) (Figure 2). In this analysis, the CPAM/CSAM was log-transformed to assure a normal distribution. The results indicate a significant negative correlation of peritoneal dialysate protein loss with $\operatorname{Ln}(\mathrm{CPAM} / \mathrm{CSAM})(\mathrm{r}=-0.532, p=0.001)$. 


\section{Kidney \\ Blood Pressure Research}

\begin{tabular}{llcc} 
Table 2. & & & Coefficient of correlation \\
Correlation & Amylase & with peritoneal dialysate protein loss & $P$-value \\
\cline { 2 - 4 } of peritone- & PSAM, U/L & 0.426 & $0.013^{*}$ \\
al dialysate & PPAM, U/L & -0.384 & $0.027^{*}$ \\
protein loss & SSAM, U/L & -0.613 & $<0.001^{*}$ \\
with perito- & SPAM, U/L & -0.183 & 0.308 \\
\cline { 2 - 4 } neal dialysa- & Abbreviations: PSAM, peritoneal dialysate saliva $\alpha$-amylase; PPAM, peritoneal dialysate \\
te and serum & pancreatic $\alpha$-amylase; SSAM, serum saliva $\alpha$-amylase; SPAM, serum dialysate pancreatic \\
amylase $(\mathrm{n}=$ & $\alpha$-amylase. Coefficients of correlation and $p$-values were calculated as via Spearman's \\
33) & rank correlation analysis due to the non-normal distribution of peritoneal dialysate and
\end{tabular}

Fig. 2. Relationship of peritoneal charge barrier (Ln[CPAM/CSAM]) and peritoneal dialysate protein loss (g/24 h). The Pearson r-value was -0.532 $(p=0.001)$. The charge barrier was calculated as the ratio of clearance between PAM and SAM (CPAM/CSAM), where $\mathrm{CPAM}=\mathrm{PPAM} \times$ peritoneal dialysate volume/SPAM and $\mathrm{CSAM}=\mathrm{PSAM} \times$ peritoneal dialysate volume/ SSAM.

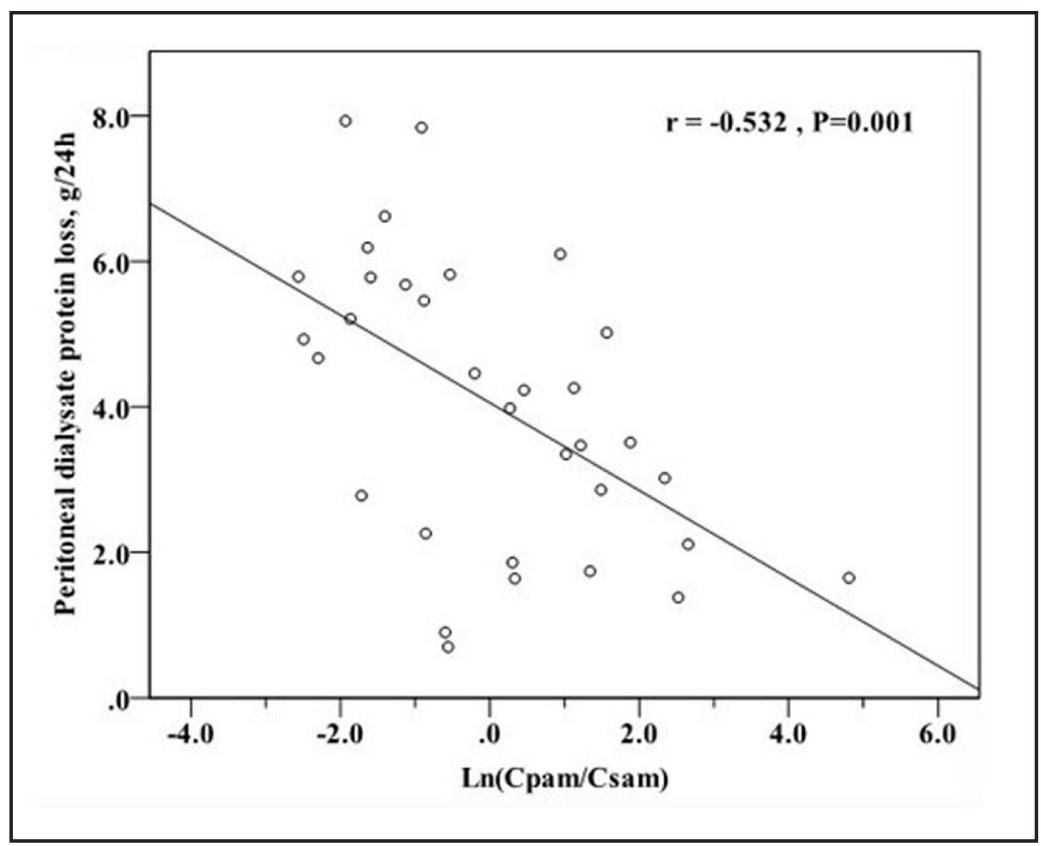

\section{Discussion}

Hypoalbuminemia is a common complication in PD patients, and protein loss during PD is a major cause of this problem. In this study, 20 of our 33 CAPD patients (61\%) had hypoalbuminemia (serum albumin $<3.5 \mathrm{~g} / \mathrm{dL}$ ), somewhat higher than previous research which indicated the incidence of hypoalbuminemia in PD patients was 20-40\%, the incidence of severe hypoalbuminemia was $8 \%$, and that hypoalbuminemia increased with the duration of PD [7].

The mean serum albumin level in our PD patients was $3.16 \pm 0.53 \mathrm{~g} / \mathrm{dL}$ after PD, below the normal lower limit of $3.5 \mathrm{~g} / \mathrm{dL}$. This could be due to urinary protein loss, consumption of a low-protein diet, anorexia, and/or increased catabolism. After PD, our patients experienced a significant decline in serum albumin but a significant increase in triglycerides. These changes may be related to loss of residual renal function, inadequate dialysis, and/or changes in patient appetite, stamina, energy level, inflammation status, or cardiovascular function [18]. The peritoneal clearance of solute may lead to loss of some nutrients, such as amino acids and proteins, which can negatively impact nutritional status [6]. Our results showed that the mean dialysate protein loss was $4.04 \pm 1.97 \mathrm{~g} /$ day. We also assessed the relationship of protein loss with nutritional status and found that protein loss was not significantly associated with serum albumin, cholesterol, or triglycerides (data not shown). 


\section{Kidney \\ Blood Pressure Research}

Thus, it is possible that compensatory liver protein synthesis was simply inadequate, similar to what occurs in the pathophysiology of nephrotic syndrome.

Our study of the mechanism of protein loss during PD indicated that PD dose was positively associated with protein loss. The reason for this result is not entirely clear, but it may be due to increased albumin convection subsequent to the increased solute exchange and ultrafiltration upon dose increase. An increased duration of PD may increase the permeability of the peritoneum and lead to peritoneal fibrosis, ultrafiltration failure [19], and possibly protein loss. However, our results indicated no significant association between duration of PD and protein loss (data not shown).

Albumin may be lost by convection, raising the question of whether the transport characteristics of the peritoneum itself may affect protein loss. We found no such relationship in the present study. A previous report suggested that the transport and clearance of macromolecular solutes is mainly molecular-selective in CAPD patients, and the charge barrier appears to play no role in this process [20]. Instead, these researchers concluded that the higher peritoneal clearance of neutral pancreatic amylase relative to anionic salivary amylase could be due to release of the former from the pancreas. However, we observed significant association between the charge barrier and peritoneal dialysate protein in our 33 CAPD patients. This difference may be explained by the inclusion of peritonitis patients in this previous study, but the exclusion of peritonitis patients in the present study. Albumin is negatively charged and is the major protein in the dialysate, so our data suggest that the disruption of the peritoneal charge barrier results in increased albumin leakage.

The present study had several limitations that should be noted. The sample size was relatively small and all patients were from a single medical center. Second, this was a single-arm study, and there was no control or experimental group. A large multi-center and multi-arm trial would clearly provide more reliable results. Finally, we cannot exclude the possibility that recorded peritoneal amylase levels are exclusively driven by transport across the peritoneal membrane.

\section{Conclusion}

Our results suggest that disruption of the peritoneal charge barrier plays an important role in dialysate protein loss in CAPD patients and confirmed that dialysate protein loss was positively associated with dialysis dose. In addition, the level of dialysate protein loss was negatively associated with the charge barrier index. These results suggest that protein loss in PD patients may be reduced if the dialysate is supplemented with negatively charged additives.

\section{Conflict of Interests}

The authors declare that they have no conflict of interest.

\section{Acknowledgements}

This study was supported by Nanjing Military Region Medicine and Health Research Surface Project (09MA099). 


\section{Kidney \\ Blood Pressure Research}

Kidney Blood Press Res 2013;37:252-258

\begin{tabular}{l|l}
\hline DOI: $10.1159 / 000350150$ & (c) 2013 S. Karger AG, Basel
\end{tabular}

Published online: July 15, 2013

www.karger.com/kbr

Yu/Chen/Li: Factors Affecting Protein Loss During CAPD

\section{References}

1 Pecoits-Filho R, Lindholm B, Stenvinkel P: The malnutrition, inflammation, and atherosclerosis (MIA) syndrome - the heart of the matter. Nephrol Dial Transplant 2002;17:28-31.

2 Meguid El Nahas A, Bello AK: Chronic kidney disease: the global challenge. Lancet 2005;365:331-340.

-3 Zoccali C, Tripepi G, Mallamaci F: Predictors of cardiovascular death in ESRD. Semin Nephrol 2005;25:358362.

-4 Ersoy FF: Improving technique survival in peritoneal dialysis: what is modifiable? Perit Dial Int 2009;29:S74-S77.

-5 Blumenkrantz MJ, Gahl GM, Kopple JD, Kamdar AV, Jones MR, Kessel M, Coburn JW: Protein losses during peritoneal dialysis. Kidney Int 1981;19:593-602.

-6 Kopple JD, Blumenkrantz MJ, Jones MR, Moran JK, Coburn JW: Plasma amino acid levels and amino acid losses during continuous ambulatory peritoneal dialysis. Am J Clin Nutr 1982;36:395-402.

7 Yeun JK, Kaysen GA: Factors influencing serum albumin in dialysis patients. Am J Kidney Dis 1998;32:S118-S125.

8 Chung SH, Chu WS, Lee HA, Kim YH, Lee IS, Lindholm B, Lee HB: Peritoneal transport characteristics, comorbid diseases and survival in CAPD patients. Perit Dial Int 2000;20:541-547.

-9 Balafa O, Halbesma N, Struijk DG, Dekker FW, Krediet RT: Peritoneal albumin and protein losses do not predict outcome in peritoneal dialysis patients. Clin J Am Soc Nephrol 2011;6:561-566.

10 Lyepoldt JK, Henderson LW: Molecular change influences transperitoneal macromolecule transport. Kidney Int 1993;43:837-844.

11 Gotloib L, Shustak A, Jaichenko J: Loss of mesothelial electronegative fixed charges during murine septic peritonitis. Nephron 1989;51:77-83.

12 Krediet RT, Struijk DG, Koomen GC, Zemel D, Boeschoten EW, Hoek FJ, Arisz L: Peritoneal transport of macromolecules in patients on CAPD. Contrib Nephrol 1991;89:161-174.

13 Fox JG, Qiun JD, O Reilly DS, Boulton-Jones JM: Assessment of glomerular charge selectivity in man by differential clearance of isoamylase. Clin Sci 1993;84:449-454.

14 Recio F, Villamil F, Recio C, Ferrer C: Utility of filtration markers to monitor the quality of glomerular function. Clin Nephrol 1992;38:S8-S13.

15 Thum CN, Oelbaum RS, Foo AY, Rosalki SB: Renal isoamylase clearance as a measurement of altered renal charge selectivity in patients with diabetes mellitus. Ann Clin Biochem 1993;35:449-453.

16 O'Donnell MD, FitzGerald O, McGeeney KF: Differential serum amylase determination by use of an inhibitor, and design of a routine procedure. Clin Chem 1977;23:560-566.

17 Brandes JC, Piering WF, Beres JA: A method to assess efficacy of CAPD: preliminary results. Adv Perit Dial 1990;6:192-196.

-18 Yao Q, Axelsson J, Heimburger O, Stenvinkel P, Lindholm B: Systemic inflammation in dialysis patients with end-stage renal disease: causes and consequences. Minerva Urol Nefrol 2004;56:237-248.

19 Kim YL: Update on mechanism of ultrafiltration failure: Perit Dial Int 2009;29:S123-S127.

20 Buis B, Koomen GC, Imholz AL, Struijk DG, Reddingius RE, Arisz L, Krediet RT: Effect of electric charge on the transperitoneal transport of plasma proteins during CAPD. Nephrol Dial Transplant 1996;11:11131120 . 